\title{
EFEITO DA TERAPIA FOTODINÂMICA ANTIMICROBIANA NO CONTROLE DO BIOFILME DENTAL CARIOGÊNICO IN VITRO
}

Dissertação apresentada à Faculdade de Odontologia de Ribeirão Preto da Universidade de São Paulo para obtenção do Título de Mestre em Ciências junto ao Programa de Odontopediatria com Área de Concentração em Odontopediatria.

Orientadora: Profa. Dra. Maria Cristina Borsato 
AUTORIZO A REPRODUÇÃO E DIVULGAÇÃO TOTAL OU PARCIAL DESTE TRABALHO, POR QUALQUER MEIO CONVENCIONAL OU ELETRÔNICO PARA FINS DE ESTUDO E PESQUISA, DESDE QUE CITADA A FONTE.

FICHA CATALOGRÁFICA

de Sousa Farias, Sofia Sampaio

Efeito da terapia fotodinâmica antimicrobiana no controle do biofilme dental cariogênico in vitro. Ribeirão Preto, 2015.

p.82 : il. ; $30 \mathrm{~cm}$

Dissertação de Mestrado apresentada à Faculdade de Odontologia de Ribeirão Preto/USP - Área de concentração: Odontopediatria.

Orientadora: Borsato, Maria Crsitina

1. Biofilmes. 2. Terapia fotodinâmica. 3. Streptococcus mutans. 4. Laser de diodo. 5. Polissacarídeos 


\section{SOFIA SAMPAIO DE SOUSA FARIAS}

DE SOUSA FARIAS, SS. EFEITO DA TERAPIA FOTODINÂMICA ANTIMICROBIANA NO CONTROLE DO BIOFILME DENTAL CARIOGÊNICO IN VITRO

Dissertação apresentada à Faculdade de Odontologia de Ribeirão Preto da Universidade de São Paulo para obtenção do Título de Mestre em Ciências.

Área de Concentração: Odontopediatria

Data da defesa:

BANCA EXAMINADORA

$\operatorname{Prof}(\mathrm{a}) . \operatorname{Dr}(\mathrm{a})$ :

Julgamento: Assinatura

Prof(a). Dr(a).:

Julgamento: Assinatura

Prof(a). Dr(a).:

Julgamento: Assinatura 



\section{DADOS CURRICULARES}

\section{SOFIA SAMPAIO DE SOUSA FARIAS}

Nascimento 27/05/1985 - Fortaleza/CE

Filiação Luiz Vandemberg de Sousa

Denise Sampaio de Sousa

2004-2009 Curso de Graduação em Odontologia

Universidade de Fortaleza

2009-2011 Curso de Pós-Graduação em Odontologia (Especialização)

Área de concentração: Ortodontia

Academia Cearense de Odontologia

2012-2012 Curso de Aperfeiçoamento

Área de concentração: Estética

Academia Cearense de Odontologia

2013-2015 Curso de Pós-Graduação em Odontologia (Mestrado)

Área de concentração: Odontopediatria

Faculdade de Odontologia de Ribeirão Preto - FORP/USP 

"O sucesso nasce do querer, da determinação e persistência em se chegar a um objetivo. Mesmo não atingindo o alvo, quem busca e vence obstáculos, no mínimo fará coisas admiráveis" (José de Alencar) 

Dedicatória 



\section{DEDICATÓRIA}

Ao meu filho Artur, que ainda não está nos meus braços, mas me deu forças e paciência pra encerrar mais uma etapa da minha vida. Já amo você pequenininho! 

Agradecimentos $E_{\text {speciais }}$ 



\section{AGRADECIMENTOS ESPECIAIS}

A Deus, por está sempre presente em minha vida, sendo meu confidente $e$ protetor, nos momentos de alegrias e de tristezas. Por permitir que eu chegasse até aqui, com muita saúde e força para superar todos os obstáculos. Por permitir que eu conhecesse pessoas maravilhosas: minha familia tão presente, meu marido André, meus presentes Artur e Nalu, e os amigos feitos nessa caminhada da vida. Agradeço pela Tua bondade infinita!

Aos meus queridos pais, Luiz e Denise, pelo amor incondicional, pela familia que construímos, pela educação, por sempre me apoiarem nas minhas escolhas, pelos puxões de orelhas ao longo da minha vida, pela confiança, por serem os maiores torcedores de todas as minhas conquistas. Me sinto realizada em poder proporcionar mais um motivo de orgulho pra vocês. Obrigada por todo amor, dedicação e por serem tão presentes, mesmo estando distantes fisicamente! Amo vocês!

Aos meus queridos irmãos, Paula e Lucas, pelo amor e carinho que nos une. Agradeço pela nossa infância, pelos nossos momentos juntos, nossas brincadeiras $e$ brigas. Vivemos tudo com muita intensidade, muitas alegrias e sem rancor. $O$ tempo passou, crescemos, e cada um seguiu seu rumo, mas nossa ligação de irmão é mais forte que tudo isso. Obrigada pelo apoio e preocupação! Amo vocês!

Ao meu marido André! Dé, se você não existisse na minha vida não estaria aqui conquistando mais esta etapa. Deus coloca pessoas certas, na hora certa. E você chegou pra me fazer feliz! Decidir sair de Fortaleza e enfrentar um mestrado depois de 5 anos de formada, não foi uma escolha tão fácil. Mas nosso amor e seu incentivo me deram forças para está aqui. Eu te agradeço pelo apoio, compreensão, paciência e pela sua alegria constante. Você é exemplo de coragem e determinação. E obrigada pelo nosso filho Artur! Te amo muito muito!!

A minha Nalu, a maior companheira e confidente dos últimos 2 anos. Sempre ao meu lado, ou deitada nos meus pés enquanto estudava ou com ciúmes do computador no meu colo. Uma cachorrinha muito especial que me mostrou um outro amor. Amo você cabritinha! 

Agradecimentos 



\section{AGRADECIMENTOS}

À minha querida orientadora, Prof. Dra. Maria Cristina Borsato, por ter me acolhido de braços abertos, pela confiança, pelo apoio e incentivo. Cris, te agradeço por todos os ensinamentos, pela orientação, pela sua alegria, pelo seu jeito tranquilo em lidar com os problemas, buscando sempre a melhor solução, pelo seu alto astral, pela sua generosidade. Suas gargalhadas são as melhores! Deus escutou minhas preces e fez eu ser sua orientada.

À Prof. Dra. Carolina Patrícia Aires, pela disposição em me receber no seu laboratório, pela confiança, pela paciência, pela tranquilidade. Obrigada por permitir a realização deste trabalho e por todo conhecimento transmitido.

À Prof. Dra. Silmara Aparecida Milori Corona, pela disponibilidade em ajudar na conclusão desta dissertação, pelos conhecimentos transmitidos, pelo apoio e atenção.

À minha parceira no laboratório, Mariana Alencar Nemezio, pela oportunidade em trabalhar na mesma linha de pesquisa, pela ajuda no decorrer deste trabalho, pelo apoio, pela paciência. A finalização desta dissertação é mérito seu também!

À Universidade de São Paulo, na pessoa do atual diretor, Prof. Dr. Marco Antonio Zago e do vice-diretor, Prof. Dr. Vahan Agopyan.

À Faculdade de Odontologia de Ribeirão Preto da Universidade de São Paulo, na pessoa do diretor Prof. Dr. Valdemar Mallet da Rocha Barros e a Vice Diretora Prof. Dra. Léa Assed Bezerra da Silva.

À Coordenação do Curso de Pós-Graduação em Odontopediatria da Faculdade de Odontologia de Ribeirão Preto da Universidade de São Paulo, na pessoa da coordenadora Profa. Dra. Raquel Assed Bezerra Segato, e da vice-coordenadora, Profa. Dra. Léa Assed Bezerra da Silva, pelo privilégio e oportunidade de ser aluna deste programa. 
À CAPES pela bolsa concedida.

Aos professores do Departamento de Clínica Infantil da Faculdade de Odontologia de Ribeirão Preto da Universidade de São Paulo, Profa. Dra. Léa Assed Bezerra da Silva, Prof. Dr. Paulo Nelson Filho, Profa. Dra. Maria Cristina Borsato, Profa. Dra. Raquel Assed Bezerra Segato, Profa. Dra. Adelvina Campos de Freitas, Profa. Dra. Alexandra Mussolino de Queiroz, Profa. Dra. Andiara de Rossi Daldegan, Profa. Dra. Kranya Victoria Díaz Serrano, Profa. Dra. Maria da Conceição Pereira Saraiva, Prof. Dr. Fabrício Kitazono de Carvalho, Prof. Dr. Fábio Lourenço Romano, Prof. Dr. José Tarcísio Lima Ferreira, Prof. Dra. Mírian Aiko Nakane Matsumoto, Prof. Dra. Maria Bernadete Sasso Stuani, Prof. Dr. Adilson Tomasin pelos ensinamentos, pelas orientações, pelo privilégio em poder conhecê-los e por fazerem parte da minha formação.

Aos funcionários do Departamento de Clínica Infantil, Dr. Francisco Wanderlei Garcia de Paula e Silva, Dra. Carolina Torres Mantovani, Dra. Marilia Pacífico Lucisano, Nilza Letícia Magalhães, Micheli Cristina Leite Rovanholo, Marco Antonio do Santos, Fatima Aparecida Jacinto Daniel, Filomena Leli Placciti, Matheus Morelli Zanela, Ditinha Rodrigues, Rosemary Alves, pelo carinho, disposição e convivência.

À querida Micheli Cristina Leite Rovanholo, pelo carinho, atenção e disposição em ajudar. Muito obrigada por tudo!

Aos funcionários do Laboratório de Bioquímica da Faculdade de Ciências Farmacêuticas de Ribeirão Preto, Ana Cristina Morseli Polizello e Luciana Ângulo, e a aluna Ana Carolina dos Santos, pela ajuda, disposição, conversas, simpatia. Muito bom ter trabalho junto a vocês!

Aos amigos da Pós-graduação, Ana Caroline Fumes, Carolina Maschietto Pucinelli, Cíntia Guimarães de Almeida, Claudia Maria Carpio Bonilla, Daniela Silva 
Barroso, Daniele Luca Longo, Danielly Cunha Araújo Ferreira, Denise de Souza Matos, Driely Barreiros, Elaine Machado Pingueiro, Francine Lorencetti da Silva, Juliana Arid, Katharina Morant Holanda de Oliveira, Késsia Suênia Fidelis de Mesquita Guimarães, Larissa Nogueira Soares Ribeiro, Leonardo Gontijo Matos, Lídia Regina da Costa Hidalgo, Maria Gabriela Flores Bracho, Mariana de Oliveira Daltoé, Mariana Alencar Nemezio, Mariele Andrade, Marina Mocardini Vilela, Paula Regina Ávila Silvano, Priscilla Coutinho Romualdo, Rodrigo Alexandre Valério, Silvana Aparecida Fernandes Polizeli, Talitha de Siqueira Mellara pela experiência compartilhada.

À turma do Mestrado, Carolina Maschietto Pucinelli, Claudia Maria Carpio Bonilla, Francine Lorencetti da Silva, Juliana Arid, Maria Gabriela Flores Bracho, Mariana de Oliveira Daltoé, Marina Moscardini Vilela, Paula Regina Ávila Silvano, Sara Silva de Oliveira, pela amizade, pela convivência maravilhosa, pela troca de conhecimentos. Vou sempre lembrar de vocês!

As minhas meninas lindas, Gaby, Clau e Saritcha, pelo companheirismo durante esses 2 anos, pela intensa amizade, pelas risadas, pelas confissões...Vocês são pessoas super especiais, cada uma com sua personalidade. Obrigada por fazerem parte da minha história aqui em Ribeirão Preto. Cada uma seguirá seu rumo na sua cidade, mas nossa ligação será eterna. Amo vocês!

As minhas nordestinas, alagoanas Fernanda e Késsia, pessoas muito queridas e especiais. Fêe, uma pessoa única, que com sua alegria conquista a todos. Agradeço por todos os momentos de risadas, de leitura de artigos, de aulas de inglês, de saídas. Kessita, minha Zé, minha irmãzinha "gêmula", tão parecidas fisicamente e internamente, uma pessoa incrível, sempre disposta me ajudar, a me escutar. Você foi essencial na conclusão deste trabalho, tirou todas minhas dúvidas. Você é um presente de Deus! Um ser iluminado, menina super responsável e dedicada, você vai longe, e eu quero está 
sempre ao seu lado, vibrando com você todas suas conquistas. Obrigada por participar tão intensamente dos momentos da minha vida. Amo vocês!

À amiga Carol Fumes, pelo disposição, pela convivência agradável, por me ajudar nos estudos pilotos, pela companhia na clínica infantil. Muito Obrigada!

Às amigas Lídia, Dani Longo e Marília pelos momentos divertidos, pelas risadas, pela amizade. Obrigada!

Aos meus amigos de Fortaleza, Andréa, Larissa, Lorena, Juliana, Anna Júlia, Camilla, Mariana, Ravena, Viviane, Lara, Idalina, Bruna, Carlos Bruno, pelo apoio e amizade verdadeira. Ficar longe de vocês não foi fácil, fizeram muita falta nesse tempo, mas sei que vocês torceram muito pelas minhas conquistas. Amo vocês!

A todos que, direta ou indiretamente, contribuíram para execução desse trabalho, a minha sincera gratidão. 
Sumário 



\section{SUMÁRIO}

RESUMO

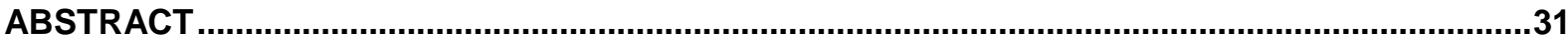

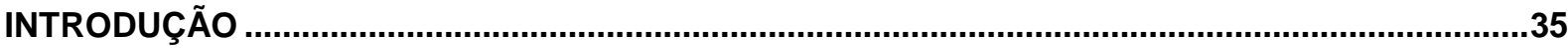

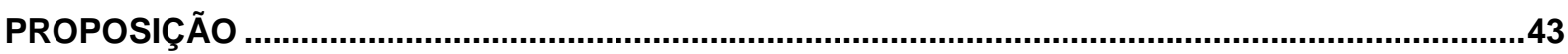

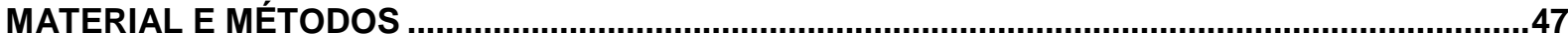

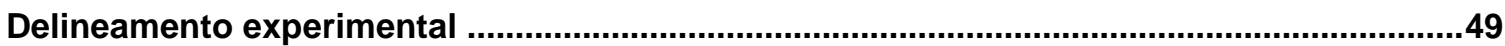

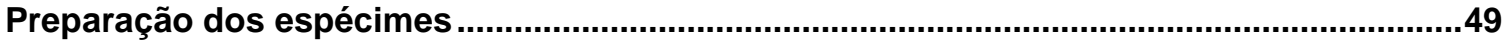

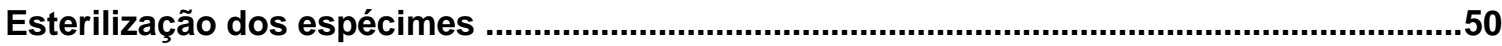

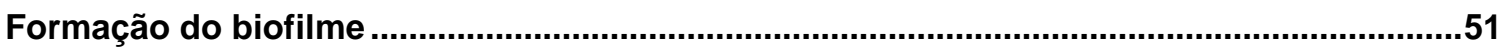

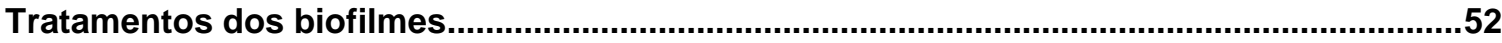

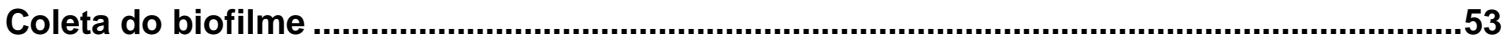

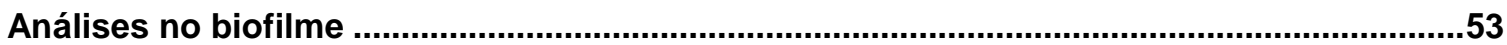

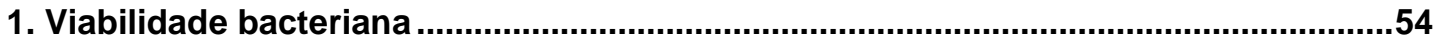

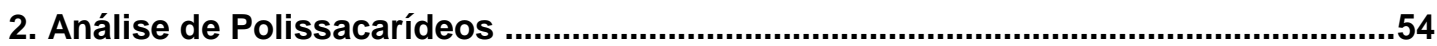

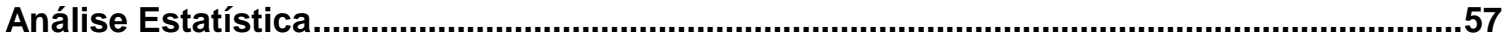

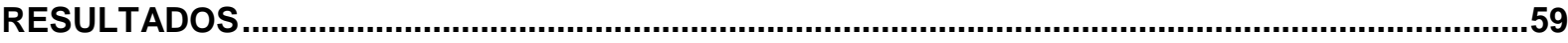

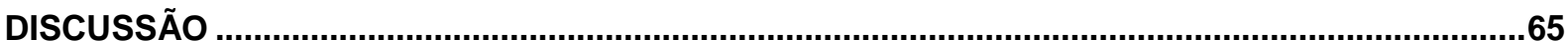

CONCLUSÃO

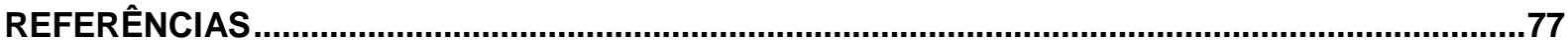



Resumo 



\section{Resumo}

DE SOUSA FARIAS, SS. Efeito da terapia fotodinâmica antimicrobiana no controle do biofilme dental cariogênico in vitro. 82p. [dissertação]. Faculdade de Odontologia de Ribeirão Preto, Universidade de São Paulo, Ribeirão Preto, 2015.

O objetivo deste estudo foi avaliar o efeito da terapia fotodinâmica antimicrobiana (TFDa), utilizando laser de baixa potência, em duas densidades de energia, associado ao azul de toluidina em biofilme de $S$. mutans. Biofilmes de $S$. mutans UA159 foram crescidos por 5 dias em discos de resina acrílica ( $3 \mathrm{~mm}$ de diâmetro $\times 2 \mathrm{~mm}$ de altura) a $37^{\circ} \mathrm{C} 5 \%$ de $\mathrm{CO}_{2}$. Os espécimes foram divididos aleatoriamente em 4 grupos de tratamento $(n=3)$ : Digluconato de clorexidina $0,12 \%$ ( $\mathrm{CHX}$, controle positivo); Solução salina a $0,89 \%(\mathrm{NaCl}$, controle negativo); Terapia fotodinâmica antimicrobiana com azul de toluidina e laser de baixa potência (densidade de energia $320 \mathrm{~J} / \mathrm{cm}^{2}$ ) (TFDa 320); Terapia fotodinâmica antimicrobiana com azul de toluidina e laser de baixa potência (densidade de energia $640 \mathrm{~J} / \mathrm{cm}^{2}$ ) (TFDa 640). Os tratamentos foram realizados $2 x /$ dia durante 3 dias. Ao final dos 5 dias, os biofilmes foram coletados e número de bactérias viáveis e a concentração de polissacarídeos extracelulares insolúveis (PECI) e intracelulares (PIC) foram determinadas e analisadas estatisticamente (ANOVA e teste de Tukey, $p<0,05$ ). O tratamento com a TFDa (320 e 640 $\mathrm{J} / \mathrm{cm}^{2}$ ) reduziu o número de bactérias viáveis em biofilmes de $S$. mutans, de uma maneira dose-dependente $(p<0,05)$. Além disso, a TFDa $640 \mathrm{~J} / \mathrm{cm}^{2}$, reduziu a viabilidade bacteriana de forma tão eficaz quanto a $\mathrm{CHX}(\mathrm{p}>0,05)$. Em relação a PECl e PIC, os grupos TFDa (320 e $\left.640 \mathrm{~J} / \mathrm{cm}^{2}\right)$ não foram significativamente diferentes de $\mathrm{CHX}(p>0,05)$. Os resultados mostraram que a terapia fotodinâmica antimicrobiana, mediada pelo azul de toluidina e laser de diodo $\left(640 \mathrm{~J} / \mathrm{cm}^{2}\right)$, pode ser uma abordagem utilizada no controle do biofilme dental cariogênico.

Palavras-chaves: biofilmes, terapia fotodinâmica, Streptococcus mutans, Laser de diodo, Polissacarídeos. 

Abstract 



\begin{abstract}
DE SOUSA FARIAS, SS. Effect of antimicrobial photodynamic therapy in the control of cariogenic dental biofilm in vitro. 82p. [dissertação]. Faculdade de Odontologia de Ribeirão Preto, Universidade de São Paulo, Ribeirão Preto, 2015.
\end{abstract}

The aim of this study was to evaluate the effect of antimicrobial photodynamic therapy (aPDT), using low-power laser, with two energy densities, associated with toluidine blue in $S$. mutans biofilm. S. mutans UA159 biofilms were grown for 5 days on acrylic resin discs (3 $\mathrm{mm}$ diameter $\times 2 \mathrm{~mm}$ height) a $37^{\circ} \mathrm{C}, 5 \%$ de $\mathrm{CO}_{2}$. The specimens were randomly divided into 4 treatment groups $(n=3): 0.12 \%$ chlorhexidine digluconate $(\mathrm{CHX}$, positive control); 0,89\% Saline ( $\mathrm{NaCl}$, negative control); Antimicrobial photodynamic therapy with toluidine blue and low power laser (energy density of $320 \mathrm{~J} / \mathrm{cm}^{2}$ ) (aPDT 320); Antimicrobial photodynamic therapy with toluidine blue and low power laser (energy density of $640 \mathrm{~J} / \mathrm{cm}^{2}$ ) (aPDT 640). Treatments were performed 2x/day for 3 days. At the end of 5 days, the biofilms were collected and the number of viable bacteria and the concentration of insoluble extracellular (IEPS) and intracellular polysaccharides (IPS) were determined and analyzed statistically (ANOVA and Tukey's test, $\mathrm{p}<0.05$ ). Treatment with aPDT (320 and $640 \mathrm{~J} / \mathrm{cm}^{2}$ ) reduced the number of viable bacteria of $S$. mutans biofilms in a dose-dependent manner $(p<0.05)$. Furthermore, the aPDT 640 group reduced the bacterial viability as effectively as CHX group ( $p>0.05)$. For IEPS and IPS, the aPDT groups (320 and $640 \mathrm{~J} / \mathrm{cm}^{2}$ ) were not significantly different $\mathrm{CHX}(\mathrm{p}>0.05)$. The results showed that the antimicrobial photodynamic therapy mediated by toluidine blue and diode laser $(640 \mathrm{~J} / \mathrm{cm} 2)$ may be an approach used to control the cariogenic dental biofilm.

Keywords: Biofilms, Photodynamic therapy, Streptococcus mutans, Diode laser, Polysaccharides. 



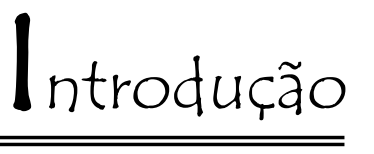





\section{INTRODUÇÃO}

A cavidade bucal é colonizada por uma gama complexa de micro-organismos, relativamente específicos e altamente inter-relacionados, que estão organizados em biofilmes. Os micro-organismos do biofilme estão aderidos tanto uns aos outros quanto às superfícies ou interfaces dos dentes, e incorporados em uma matriz polimérica extracelular, de origem bacteriana, que inclui água e nutrientes (Marsh e Bradshaw, 1997; Costerton et al., 1999). Doenças relacionadas com o biofilme, como a cárie dentária e doença periodontal apresentam riscos graves à saúde bucal e geral (Wilson et al., 1996).

A cárie dentária é uma doença muito comum mundialmente, afetando 60-90\% das crianças em idade escolar e a grande maioria dos adultos (Petersen, 2003). É causada pela produção de ácidos por bactérias acidogênicas e acidúricas do biofilme dental após a exposição a carboidratos fermentáveis (Svensater et al., 2003; Marsh, 2010), principalmente à sacarose, o que resulta na destruição localizada de tecidos mineralizados dentais. A doença se inicia com um desequilíbrio entre os processos de desmineralização e remineralização na superfície do esmalte (van Houte, 1994).

Os estreptococos são referidos como sendo as primeiras bactérias que colonizam as superfícies bucais (van Houte, 1994) e compreendem a maioria dos micro-organismos do biofilme dental (Pratten et al., 2003). Os Streptococcus mutans são considerados os agentes causadores direto da cárie dentária (van Houte, 1994; Lemos e Burne, 2008), por serem tipos específicos de bactérias produtoras de ácido. Estas bactérias aderem à película salivar do esmalte e a outras bactérias do biofilme, criando um maior risco de desenvolvimento de cavidades de lesões de cárie (Takahashi e Nyvad, 2011).

A capacidade de $S$. mutans para formar um biofilme é devido, principalmente, à secreção de enzimas como as glicosiltransferases (Almeida et al., 2002). Estas enzimas são capazes de sintetizar, a partir da sacarose, os glucanos, os quais são polissacarídeos extracelulares insolúveis (PECI) (Bowen e Koo, 2011) que são importantes na formação do biofilme dental e, portanto, na patogênese da cárie dentária, pois possuem capacidade para 
promover a adesão em várias superfícies sólidas. Além dos $\mathrm{PECl}$, os $S$. mutans sintetizam polissacarídeos intracelulares (PIC) que são fontes de ácido exógeno quando o açúcar não é suficiente ou está ausente (Hamada e Slade, 1980). A associação de altas concentrações de PECI, elevado consumo de sacarose, biofilme visível e micro-organismos cariogênicos é considerado um alto risco para o desenvolvimento de lesões de cárie (Parisotto et al., 2015).

A remoção mecânica do biofilme dental e a higiene bucal adequada são os tratamentos mais comumente utilizados. No entanto, estes podem ser objeto de baixa adesão do paciente (Löe, 2000). Existe um interesse crescente em substituir, ou complementar, medidas terapêuticas mecânicas com uso de antissépticos ou antibióticos. No entanto, a utilização generalizada de tais agentes é motivo de preocupação uma vez que pode resultar no desenvolvimento de resistência nos organismos (Wilson et al., 1996). Além disso, estudos demonstram que os biofilmes estão em um estado fisiológico que os diferem de bactérias planctônicas e tendem a ser menos suscetíveis a agentes antimicrobianos (Davey e O'Toole, 2000).

A clorexidina ocupa papel de destaque dentre os antissépticos utilizados em Odontologia e é considerada padrão ouro para controle químico do biofilme (Jones, 1997). Caracteriza-se por ser um detergente catiônico que possui um amplo espectro de ação (Zanata e Rösing, 2007). O seu mecanismo de ação antibacteriano é explicado pelo fato da molécula catiônica da clorexidina ser rapidamente atraída pela carga negativa da superfície bacteriana, sendo adsorvida à parede celular por interações eletrostáticas, provavelmente por ligações hidrofóbicas ou por pontes de hidrogênio. A clorexidina, em doses elevadas, causa precipitação e coagulação das proteínas citoplasmáticas e morte bacteriana e, em doses mais baixas, a integridade da parede celular é alterada, resultando num extravasamento dos componentes bacterianos de baixo peso molecular (Rölla e Melsen, 1975). Apesar da clorexidina apresentar substantividade, o uso da mesma é limitado pelos seus efeitos colaterais, como o manchamento de dentes, restaurações, próteses e língua, alterações do paladar, sensação de queimação em tecidos moles e lesões descamativas e ulcerações da mucosa gengival (Autio-Gold, 2008). Devido as muitas limitações de medidas 
antibacterianas, incluindo a resistência aos antibióticos e os efeitos adversos da clorexidina, vários estudos tem sugerido a Terapia Fotodinâmica (TFD) como uma possível alternativa para complementar as terapias mecânicas convencionais nas diferentes áreas da saúde (Müller et al., 2007; Mang et al., 2012).

Os primeiros estudos sobre Terapia Fotodinâmica foram realizados por Lipson e Schwartz, em 1960, que observaram que a injeção de preparações cruas de hematoporfírina levou a fluorescência de lesões neoplásicas visualizadas durante a cirurgia. A partir dessa substância, foi obtida uma mistura contendo várias porfirinas, monômeros, dímeros e oligômeros, a qual foi parcialmente purificada para formar o Photofrin $\AA$, um tipo de fotossensibilizador amplamente utilizado na TFD clínica. Os resultados de estudos préclínicos e clínicos realizados em todo o mundo ao longo de um período de 25 anos têm estabelecido a terapia fotodinâmica como uma abordagem de tratamento útil para alguns tipos de câncer. A TFD envolve a administração de um agente de fotossensibilização localizador de tumor, seguido de ativação do agente por uma luz de comprimento de onda específico. Esta terapia resulta em uma sequência de processos fotoquímicos e fotobiológicos que causam um dano irreversível aos tecidos do tumor (Dougherty et al., 1998).

A TFD quando aplicada em micro-organismos está sendo denominada, Inativação Fotodinâmica de Micro-organismos (em inglês, Photodynamic inactivation of microorganisms - PIM), Quimioterapia Fotodinâmica Antimicrobiana (em inglês, Photodynamic antimicrobial chemotherapy - PACT) ou, Terapia Fotodinâmica Antimicrobiana (em inglês, Antimicrobial Photodynamic Therapy - aPDT), e é uma opção complementar, que tem se mostrado bastante promissora na redução de micro-organismos bucais humanos in vitro e in vivo (Wainwright, 1998; Gad et al., 2004; Núñez et al., 2013).

No caso de tratamentos de tecidos infectados, a TFDa é indicada para o controle do crescimento microbiano e para a indução da morte celular microbiana, porém sem causar danos irreversíveis ao tecido do hospedeiro. Assim, o objetivo é obter a morte seletiva dos micro-organismos, mas não das células humanas. Representa uma alternativa 
antibacteriana, antifúngica, antiviral para o tratamento e organismos resistentes a drogas (Núñez et al., 2013).

A TFDa baseia-se no princípio de que um corante fotoativável, conhecido como fotossensibilizador, se liga à célula-alvo e são ativados por uma luz de comprimento de onda adequado. Durante este processo, espécies de oxigênio, tais como oxigênio singleto e radicais livres, são formados, e estes produzem um efeito tóxico para a célula (Weishaupt et al., 1976; Dougherty et al., 1998; O’Neill et al., 2002; Al-Watban e Zhang, 2005; Lima et al., 2009; Guglielmi et al., 2011; Kurek et al., 2011; Mang et al., 2012). Por meio da irradiação com luz no intervalo visível do espectro, o fotossensibilizador passa por uma transição de um "estado fundamental" de baixa energia a uma energia superior, o qual é excitado para o seu estado tripleto, e a energia é transferida para o oxigênio molecular. O oxigênio singleto altamente reativo é capaz de reagir e destruir o sistema biológico das células (Dougherty et al., 1998; Araújo et al., 2014). O oxigênio singleto $\left({ }^{1} \mathrm{O}_{2}\right)$ induz processos antioxidantes, deterioram tecidos biológicos, destroem componentes essenciais celulares e modificam as atividades metabólicas de forma irreversível (Hamblin e Hasan, 2004). Os locais críticos de ação do oxigênio singleto incluem as mitocôndrias, o DNA e as membranas lipídicas (Schneider et al., 2012).

O azul de toluidina é um tipo de corante usado como fotossensibilizador na TFDa. É classificado como fenotiazínico, hidrofílico e catiônico (carregado positivamente) (Núñez et al., 2013). Para promover um efeito letal sobre as células bacterianas específicas, o fotossensibilizador precisa ser seletivo para determinadas células procariotas (Araújo et al., 2014). A inativação fotodinâmica de bactérias baseia-se na premissa de que o corante pode passar pela parede celular e acumular-se no interior na célula, o que se torna crítico para a indução de danos irreversíveis a bactérias após irradiação (Rolim et al., 2012).

Fontes de luz vermelha $(630-700 \mathrm{~nm})$ tem sido amplamente utilizadas em TFDa, devido aos seus comprimentos de onda que podem penetrar eficazmente tecidos biológicos (Wilson e Patterson, 1986). A literatura científica relata que a interação entre essas fontes de luz e os fotossensibilizantes que absorvem neste comprimento de onda, como o azul de 
metileno, azul de toluidina e verde malaquita, pode resultar em morte microbiana significativa (O'Neill et al., 2002; Zanin et al., 2005, 2006; Bevilacqua et al., 2007; Lima et al., 2009; Guglielmi et al., 2011; Pereira et al., 2011; Vahabi et al., 2011; Rolim et al., 2012; de Melo et al., 2013).

Existem na literatura científica muitos estudos que comprovaram a inativação de bactérias por meio da TFDa, utilizando diferentes tipos de fontes de luz, associados com diversos corantes. Porém nenhum estudo comparou a TFDa com um método antibacteriano considerado padrão ouro, o digluconato de clorexidina $0,12 \%$, muito utilizado na clínica odontológica. Assim, há a necessidade de mais estudos que comparem a TFDa com métodos antibacterianos. 

Proposição 



\section{ProposiçÃo}

O objetivo deste estudo é avaliar o efeito da Terapia Fotodinâmica antimicrobiana (TFDa), utilizando laser de baixa potência, em duas densidades de energia, associado ao azul de toluidina em biofilme de $S$. mutans in vitro, analisando a viabilidade bacteriana e a presença de polissacarídeos extracelulares insolúveis e intracelulares. 

Material e Métodos 



\section{MATERIAL e MÉtodos}

\section{Delineamento experimental}

O Fator em estudo foi o Método de controle do biofilme dental: Terapia fotodinâmica antimicrobiana em diferentes densidades de energia - TFDa $320 \mathrm{~J} / \mathrm{cm}^{2}$ e TFDa $640 \mathrm{~J} / \mathrm{cm}^{2}$; Digluconato de clorexidina - $\mathrm{CHX} \mathrm{0,12 \%} \mathrm{(controle} \mathrm{positivo)} \mathrm{e} \mathrm{solução} \mathrm{salina} \mathrm{-}$ $\mathrm{NaCl}$ 0,89\% (controle negativo). O delineamento do estudo foi realizado em blocos completos e casualizados, sendo a amostra composta por 12 culturas de biofilmes de $S$. mutans, divididos aleatoriamente em 4 grupos. A amostra do experimento foi realizada em triplicata $(n=3)$ e as variáveis de respostas foram obtidas por meio da análise quantitativa da viabilidade bacteriana expressa em unidades formadoras de colônia (UFC) por $\mathrm{mm}^{2}$ da área do espécime, dos polissacarídeos extracelulares insolúveis $(\mathrm{PECl})$ e dos polissacarídeos intracelulares (PIC), ambos expressos em peso $(\mu \mathrm{g})$ por $\mathrm{mm}^{2}$ da área do espécime.

\section{Preparação dos espécimes}

Foram confeccionados, a partir de uma matriz de teflon circular com um orifício central, 12 discos em resina acrílica de $3 \mathrm{~mm}$ de diâmetro por $2 \mathrm{~mm}$ de espessura. A manipulação da resina acrílica autopolimerizável (pó e líquido) (JET - Artigos Odontológicos Clássico Ltda., Campo Limpo Paulista, SP, Brasil) foi realizada de acordo com as instruções do fabricante. Previamente, o orifício da matriz foi isolado com líquido isolante (Cel - Lac, S.S. White Artigos Dentários Ltda., Rio de Janeiro, RJ, Brasil), para que a resina acrílica não aderisse à matriz. A resina acrílica manipulada foi inserida no orifício e foi prensada com uma placa de vidro por 10 minutos. Após o tempo de presa, o disco em resina acrílica foi removido da matriz para realizar o acabamento, removendo-se os excessos da resina acrílica com lâmina de bisturi $n^{0} 15$.

A análise dos discos de resina acrílica foi realizada com lupa estereoscópica (Leica S6D Stereosom, Leica Microsystems Argóvia, Suíça) com aumento de 40x. Aqueles que apresentaram bolhas de ar ou falhas foram removidos do estudo. 
O discos de resina acrílica selecionados foram envoltos por um dispositivo de fio ortodôntico para amarrilho CrNi redondo diâmetro 0,20 mm (.008") (Morelli Ortodontia, Sorocaba, SP, Brasil). O fio foi trançado com porta-agulha Mathieu (Ortho-pli, Filadélfia, Pensilvânia, EUA) até atingir $1,5 \mathrm{~cm}$ de comprimento. Outro fio ortodôntico Morest Standart CrNi retangular 0,48 mm x 0,63 mm (.019" x 0.25") (Morelli Ortodontia, Sorocaba, SP, Brasil) de $2,5 \mathrm{~cm}$ foi colado perpendicularmente ao fio de amarrilho com cola instantânea (Super bonder, Loctite, Henkel Ltda., Itapevi, SP, Brasil). Esse dispositivo foi confeccionado com a finalidade de facilitar a manipulação do espécime e de mantê-lo mergulhado dentro do meio de cultura (Figura 1).

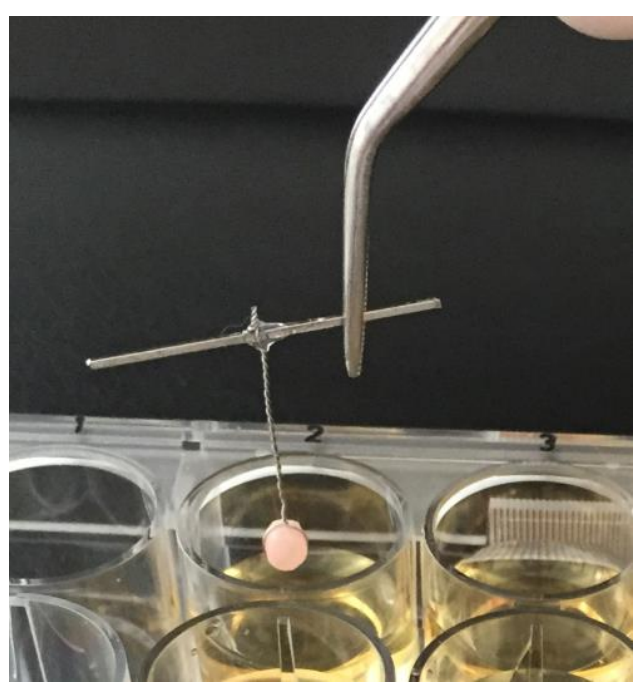

Figura 1. Disco de resina acrílica associado a dispositivo de fio de aço.

\section{Esterilização dos espécimes}

Os espécimes (dispositivo em aço + disco de resina acrílica) foram colocados em grau cirúrgico e levados para esterilização no Hospital das Clínicas da Faculdade de Medicina de Ribeirão Preto - USP. A esterilização foi feita por meio de um equipamento de Raios-X (Rad Source; Modelo RS-2000). Os parâmetros utilizados incluíram potencial de energia de $160 \mathrm{KVp}$, corrente de $25 \mathrm{mAs}$ e filtro de $0,3 \mathrm{mmCu}$. A dose aplicada foi de 100 Gray por 760 segundos. 


\section{Formação do Biofilme}

Para a formação do biofilme dentário cariogênico in vitro foi empregado o protocolo de produção de biofilme monoespécie em modelo "Miséria e Fartura" descrito por Ccahuana-Vásquez e Cury (2010), com duração de 5 dias. Cepas de Streptococcus mutans UA159, gentilmente cedidas pelo Prof Jaime A. Cury da FOP-UNICAMP, foram transferidas para um meio de baixo peso molecular (LMW), o UTYEB (Meio de Extrato de levedura Triptona) contendo glicose $1 \%$ e incubadas em estufa de anaerobiose (Sanyo Eletric Biomedical Co., Ltd., Osaka, Japão), a $37^{\circ} \mathrm{C}$ e $5 \%$ de $\mathrm{CO}_{2}$, com o objetivo de reativar os micro-organismos. Em seguida, foi realizado um "streak" desse caldo em placas de Brain Heart Infusion (BHI) Ágar, as quais ficaram mantidas em estufa $\left(37^{\circ} \mathrm{C}, 5 \%\right.$ de $\left.\mathrm{CO}_{2}\right)$. Para 0 preparo da cultura iniciadora ("starter"), foram coletadas colônias de uma placa de BHI ágar

e transferidas assepticamente para um novo meio de LMW e glicose, os quais foram mantidos em estufa $\left(37^{\circ} \mathrm{C}, 5 \%\right.$ de $\left.\mathrm{CO}_{2}\right)$. Doze espécimes foram incubados individualmente em poços contendo $2 \mathrm{~mL}$ da mistura de meio LMW, glicose e das bactérias da cultura iniciadora e colocados em estufa $\left(37^{\circ} \mathrm{C}, 5 \%\right.$ de $\left.\mathrm{CO}_{2}\right)$. Os biofilmes formados foram transferidos para novos poços contendo um novo meio LMW e glicose, sendo expostos durante $1 \mathrm{~min}$, 8x/dia, à solução de sacarose 10\%, em horários pré-determinados (08:00, $09: 30,11: 00,12: 30,14: 00,15: 30,17: 00$ e 18:30h). Este protocolo foi repetido por mais 3 dias e após cada exposição à sacarose os espécimes com biofilme foram lavados em $\mathrm{NaCl}$ 0,9\% (Fluxograma 1a).

O biofilme foi submetido aos métodos de controle do biofilme (tratamentos) 2 vezes ao dia (8:00 e 17:00) após o banho de sacarose. A troca do meio foi realizada a cada 24 horas. Durante o processo de formação do biofilme e da realização dos tratamentos foi realizada o método de Coloração Gram em um esfregaço inoculado e analisadas ao microscópio óptico de luz (Olympus Corporation, Tóquio, Japão) a fim de controlar a pureza da cultura. 


\section{Tratamentos dos biofilmes}

Os biofilmes formados ao redor dos espécimes foram submetidos a um dos 4 tratamentos $(n=3)$ : Digluconato de clorexidina $0,12 \%(\mathrm{CHX}$, controle positivo); Solução salina $0,89 \%(\mathrm{NaCl}$, controle negativo); Terapia fotodinâmica antimicrobiana com azul de toluidina e laser de baixa potência (densidade de energia $320 \mathrm{~J} / \mathrm{cm}^{2}$ ) (TFDa 320); Terapia fotodinâmica antimicrobiana com azul de toluidina e laser de baixa potência (densidade de energia $\left.640 \mathrm{~J} / \mathrm{cm}^{2}\right)$ (TFDa 640).

Para o grupo controle positivo (Grupo CHX), o digluconato de clorexidina $20 \%$ (Sigma - Aldrich Brasil Ltda., São Paulo, SP, Brasil) foi diluído a 0,12\% em água destilada estéril em fluxo laminar. Os espécimes com biofilme foram banhados em $2 \mathrm{~mL}$ dessa solução por um 1 minuto. Os espécimes do grupo $\mathrm{NaCl}$ foram mergulhados em $2 \mathrm{~mL}$ de solução salina ( $\mathrm{NaCl}$ 0,89\%) por 1 minuto.

Nos grupos que foram empregados a terapia fotodinâmica antimicrobiana (grupos TFDa 320 e TFDa 640), os espécimes com biofilme foram mergulhados em $2 \mathrm{~mL}$ do corante azul de toluidina por um período de 5 minutos. O corante azul de toluidina (Merck Millipore Corporation, Darmstadt, Alemanha) foi preparado no Laboratório de Bioquímica da Faculdade de Ciências Farmacêuticas de Ribeirão Preto - USP, a uma concentração 0,01\% em água destilada e filtrado, dentro do fluxo laminar, por meio de uma membrana de polietersulfona de 0,22 $\mu \mathrm{m}$ (KASVI, Curitiba, PR, Brasil). Após a filtração o corante foi colocado em tubo falcon envolto por papel alumínio e armazenado no escuro. Após o tempo de exposição ao corante, os espécimes foram expostos a fonte de luz. O laser de baixa potência utilizado foi um laser de diodo, fosfato de alumínio índio gálio (InGaAIP) (Whitening Lase II - DMC, São Carlos, SP, Brasil) com um comprimento de onda de 660 nm, diâmetro da fibra de 600 um e potência de $100 \mathrm{~mW}$. Os parâmetros adotados foram: Grupo TFDa 320 - Densidade de energia de $320 \mathrm{~J} / \mathrm{cm}^{2}$, tempo de irradiação de 90 segundos em cada face circular do espécime e energia total de 9 J; e Grupo TFDa 640 - Densidade de energia de $640 \mathrm{~J} / \mathrm{cm}^{2}$, tempo de irradiação de 180 segundos em cada área circular do espécime e energia total de $18 \mathrm{~J}$. (Tabela 1). 
Tabela 1. Protocolo usado para irradiação com laser de diodo (InGaAIP).

\begin{tabular}{cccccc} 
Grupos & $\begin{array}{c}\text { Comprimento } \\
\text { de onda }(\mathbf{n m})\end{array}$ & $\begin{array}{c}\text { Densidade de } \\
\text { Energia }\left(\mathbf{J} / \mathbf{c m}^{2}\right)\end{array}$ & Energia $(\mathbf{J})$ & $\begin{array}{c}\text { Potência } \\
(\mathbf{m W})\end{array}$ & $\begin{array}{c}\text { Tempo de } \\
\text { irradiação (seg) }\end{array}$ \\
\hline TFDa $\mathbf{3 2 0}$ & 660 & 320 & 9 & 100 & $90+90$ \\
TFDa $\mathbf{6 4 0}$ & 660 & 640 & 18 & 100 & $180+180$ \\
\hline
\end{tabular}

Após os tratamentos, os espécimes de todos os grupos foram lavados três vezes com solução de $\mathrm{NaCl}$ 0,9\%, para remoção do excesso das soluções (Ccahuana- Vásquez; Cury 2010) (Fluxograma 1b).

Durante todo o experimento, os procedimentos que envolveram o corante azul de toluidina e o digluconato de clorexidina foram realizados no escuro ou sob luz extremamente suave para evitar a ocorrência de fototoxicidade não intencional.

\section{Coleta do Biofilme}

Após a aplicação dos métodos de controle do biofilme e lavagem em solução de $\mathrm{NaCl}(0,9 \%)$, os espécimes $(n=3)$ foram transferidos individualmente para tubos de microcentrífuga contendo $1 \mathrm{~mL}$ de $\mathrm{NaCl}(0,9 \%)$ previamente nomeados. As amostras (Eppendorf + espécime + biofilme) foram sonicadas (Model 505 Sonic Dismembrator, Fisher Scientific, Pittsburgh, Pensilvânia, EUA) com 1 pulso de 15 segundos com amplitude de 20\%. A suspensão resultante (diluição 0 ou inicial) foi diluída em série (1:10, 1:100, 1:1000; 1:10000; 1:100000; 1:1000000; 1:10000000 e 1:100000000) em eppendorfs com $900 \mu \mathrm{L}$ de $\mathrm{NaCl}(0,9 \%)$. Alíquotas da suspensão foram utilizadas para determinar a viabilidade do biofilme bacteriano e análise dos polissacarídeos (Aires et al., 2008) (Fluxograma 1c).

\section{Análises no biofilme}

As análises no biofilme foram conduzidas de acordo com Aires et al. (2008) e serão descritas a seguir. 


\section{Viabilidade bacteriana}

Para avaliação da viabilidade bacteriana, 2 gotas de $20 \mu \mathrm{L}$ de cada diluição foram plaqueadas em Brain Heart Infusion Ágar (BHI Ágar) para determinar a viabilidade de $S$. mutans. As placas foram incubadas por $48 \mathrm{~h}$ à $37^{\circ} \mathrm{C}$ em estufa de anaerobiose $\left(37^{\circ} \mathrm{C}, 5 \%\right.$ de $\mathrm{CO}_{2}$ ). As colônias foram contadas uma lupa estereoscópica (Carl Zeiss Microimaging $\mathrm{GmbH}$, Göttingen, Alemanha), e a contagem da população de micro-organismos foi expressa em unidades formadoras de colônia (UFC) por $\mathrm{mm}^{2}$ de área do espécime (Fluxograma 1c).

\section{Análise de Polissacarídeos}

O restante da suspensão sonicada do biofilme foi centrifugada a $10.000 \mathrm{~g}$ durante 5 minutos a $4^{\circ} \mathrm{C}$ (Centrífuga 5810R, Eppendorf AG, Hamburgo, Alemanha). O sobrenadante contendo os polissacarídeos extracelulares solúveis foi recolhido. O precipitado foi lavado com $100 \mu \mathrm{L}$ de solução salina, centrifugado e o sobrenadante foi recolhido novamente. Para o precipitado, $400 \mu \mathrm{L}$ de $\mathrm{NaOH} 1 \mathrm{M}$ foram adicionados para extração dos polissacarídeos extracelulares insolúveis (PECI) (Cury et al., 1997). O eppendorf foi agitado em vórtex, agitado por 15 minutos, centrifugado e o sobrenadante foi transferido para outro eppendorf chamado PECI. O precipitado foi lavado com $100 \mu \mathrm{L}$ de $\mathrm{NaOH} 1 \mathrm{M}$, centrifugado e o sobrenadante foi adicionado ao eppendorf $\mathrm{PECl}$, no qual foram adicionados 3 volumes de etanol frio. Para o eppendorf contendo o precipitado residual, $400 \mu \mathrm{L} \mathrm{NaOH} 1 \mathrm{M}$ foram para extração de polissacarídeo intracelular (PIC) (Tenuta et al., 2006). Este tubo foi homogeneizado em vórtex, aquecido durante 15 minutos a $100^{\circ} \mathrm{C}$, centrifugado e 0 sobrenadante foi transferido para outro tubo chamado PIC. O precipitado foi lavado e o PIC extraído foi recuperado como descrito para a extração dos PECI.

Os eppendorfs contendo etanol frio com PECI ou PIC foram mantidos durante 30 minutos a $-20^{\circ} \mathrm{C}$, em seguida centrifugados e os precipitados foram lavados $2 x$ com etanol frio a $70 \%$. Os polissacarídeos precipitados foram ressuspensos em $250 \mu \mathrm{L}$ de $\mathrm{NaOH} 1 \mathrm{M} \mathrm{e}$ os hidratos de carbono totais foram estimados pelo método de fenol sulfúrico (Dubois et al., 1956), utilizando glicose como padrão. Os resultados foram normalizados para a área do espécime. 
a)
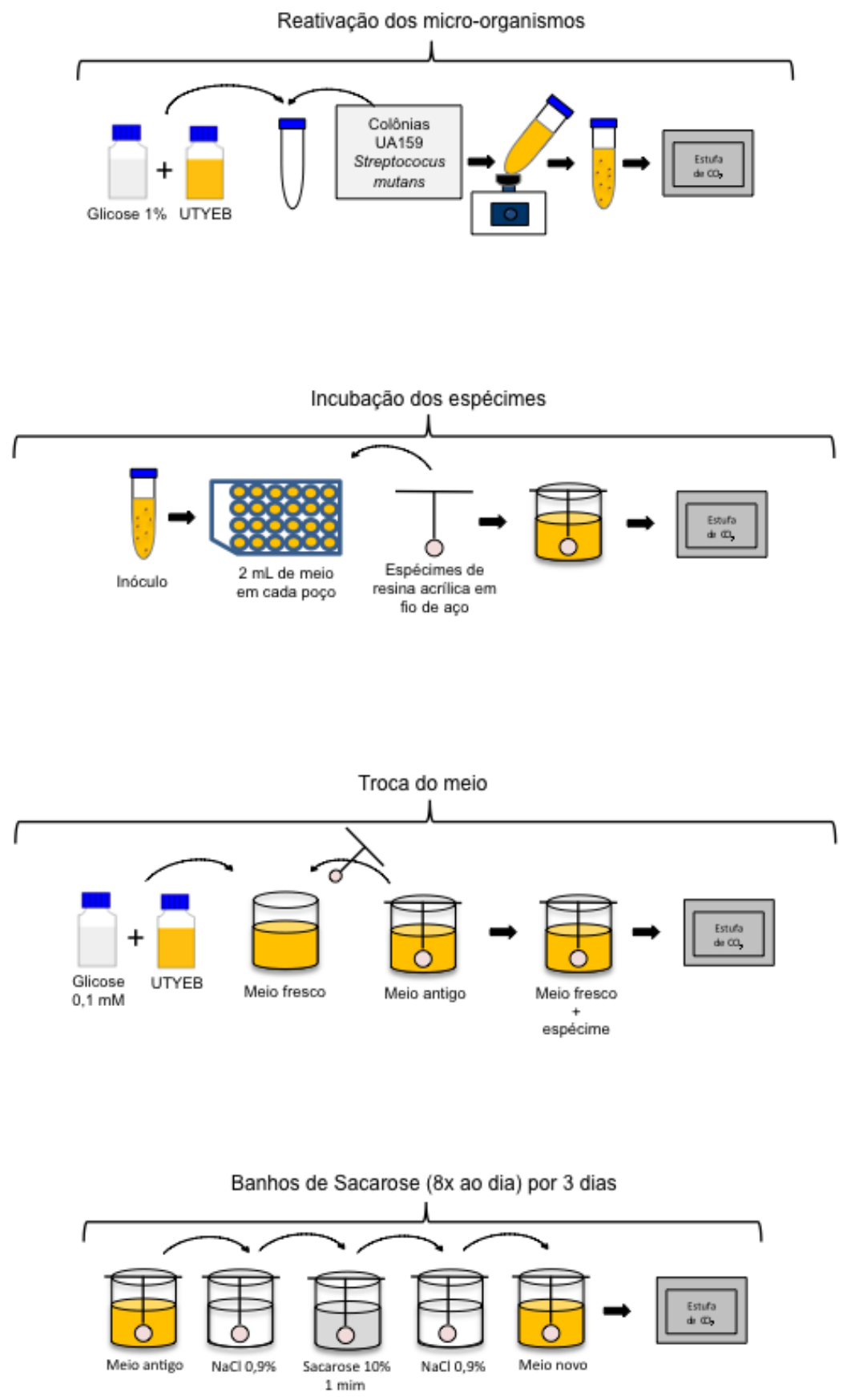

Fluxograma 1a. Fluxograma do estudo: formação de biofilme in vitro monoespécie (S. mutans) conforme modelo "Miséria e Fartura" descrito por Ccahuana-Vásquez e Cury (2010) 
b)

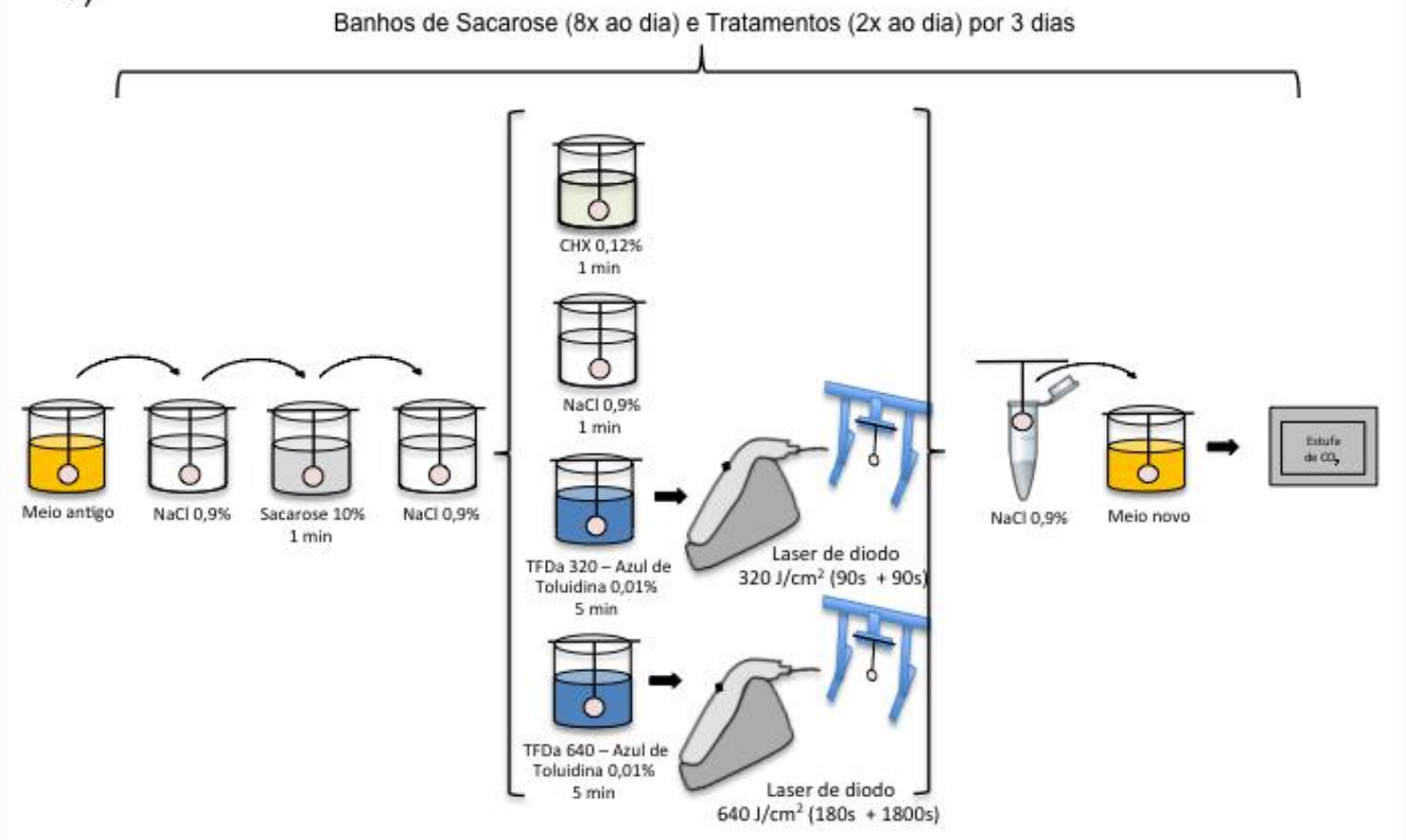

c)
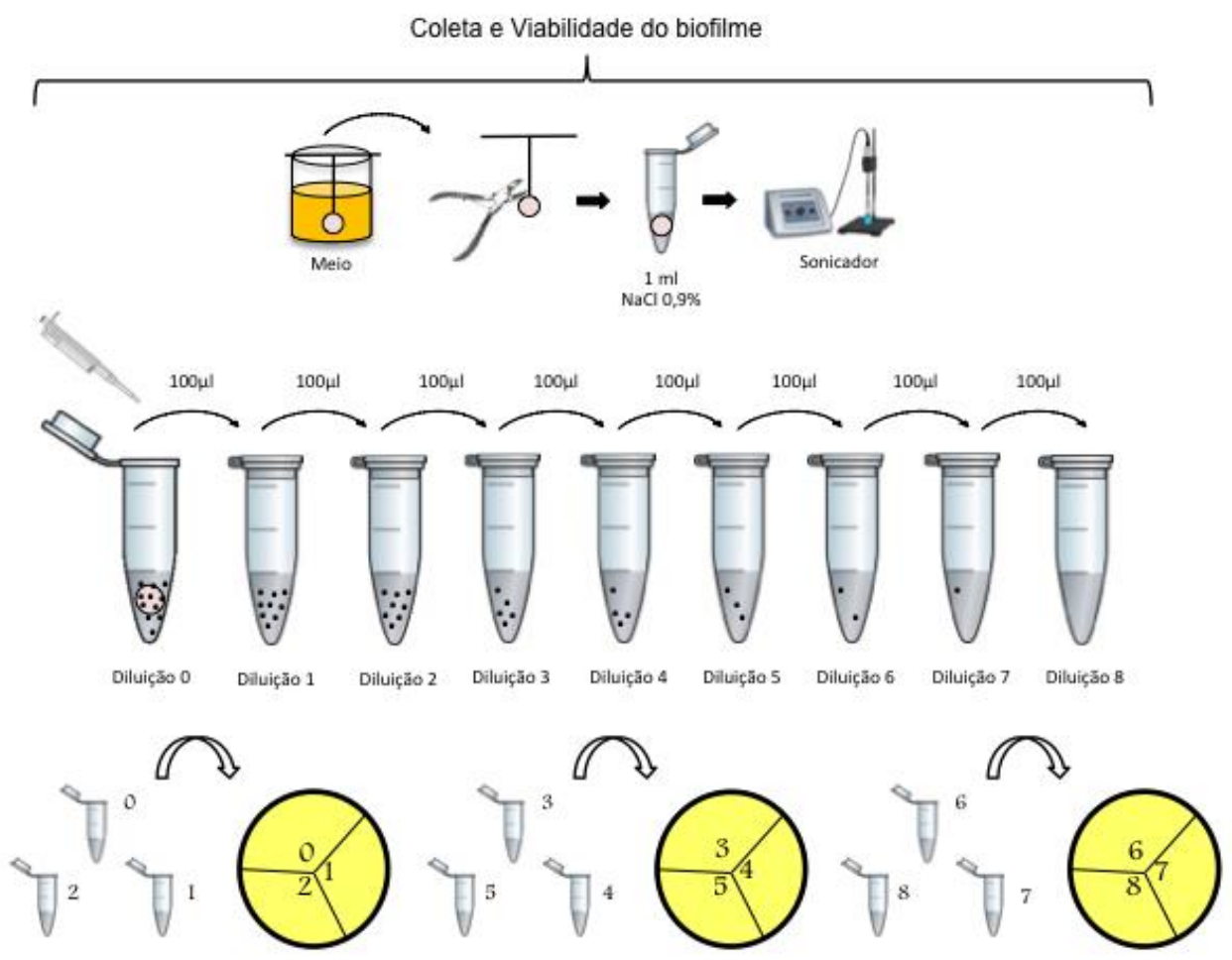

Fluxograma 1b e c. Fluxograma do estudo: métodos de controle do biofilme dental cariogênico, coleta e viabilidade do biofilme. 


\section{Análise Estatística}

Para comparação das médias entre os tratamentos, foi usada a análise de variância (ANOVA). Uma vez avaliada a existência de diferença entre, pelo menos, duas dentre as médias comparadas, foi feito um teste auxiliar, nesse caso o teste de Tukey-Kramer foi eleito, em nível de significância de 5\%.

Os dados da viabilidade bacteriana foram avaliados pela a técnica de análise de variância baseada em postos (Rank Based ANOVA) que é uma hibridação entre o teste paramétrico (ANOVA + Tukey) e não paramétrico (Teste de Kruskal-Wallis).

A pressuposição de normalidade dos erros foi avaliada em todos os casos por meio de gráficos, do teste de Shapiro-Wilk e dos coeficientes de assimetria e curtose.

As análises foram processadas por meio do uso do sistema SAS (SAS Institute Inc. The SAS System, release 9.3. SAS Institute Inc., Cary:NC, 2010) e em todos os testes estatísticos foi adotado o nível de significância de 5\%. 

Resultados 



\section{REsultados}

Os resultados, descritos na tabela 2 e figura 2, mostram a média dos valores do número de Unidades Formadoras de Colônias (UFC) pela área do espécime em $\mathrm{mm}^{2}$. Podese observar que o grupo TFDa 640 foi semelhante estatisticamente ao grupo tratado com $\mathrm{CHX}(\mathrm{p}>0,05)$ (tabela 4), apresentando a mesma eficiência na morte celular. O tratamento com TFDa 320 foi estatisticamente diferente dos demais grupos, apresentando maior viabilidade bacteriana em comparação aos grupos TFDa 640 e $\mathrm{CHX}(p<0,05)$ e menor número de bactérias que o grupo $\mathrm{NaCl}(\mathrm{p}<0,05)$. $\mathrm{O}$ tratamento com solução salina foi diferente estatisticamente da CHX, TFDa 320 e 640 ( $p<0,05)$, apresentando viabilidade maior.

Tabela 2. Viabilidade bacteriana de biofilme (S. mutans) de acordo com tratamento.

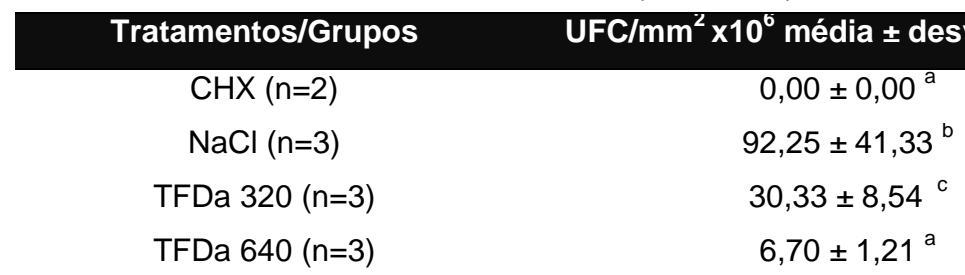

Os dados são expressos como média (desvio padrão) de unidades formadoras de colônias pela área do espécime $\left(\mathrm{UFC} / \mathrm{mm}^{2}\right)$. As diferenças estatísticas são indicadas por letras minúsculas diferentes (teste de Tukey, $p<0,05$ ) (valor de F: 40,25).

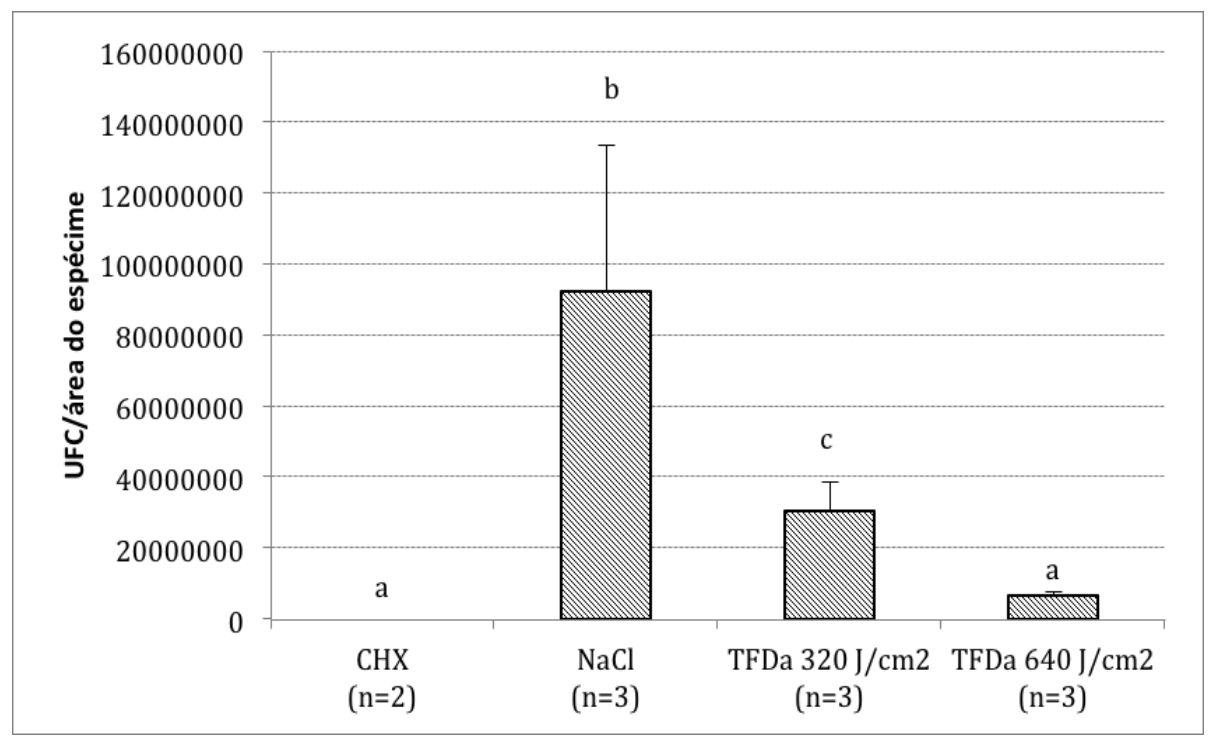

Figura 2. Efeitos dos diferentes tratamentos sobre a viabilidade bacteriana de biofilme (Streptococcus mutans). As diferenças estatísticas são indicadas por letras minúsculas diferentes (teste de Tukey, $p<0,05$ ). 
A tabela 3 demonstra a média da concentração de polissacarídeos extracelulares insolúveis (PECI) e de polissacarídeos intracelulares (PIC) de biofilmes crescidos pela área do espécime $\left(\mathrm{mm}^{2}\right)$ após os tratamentos. Pode-se observar que não houve diferença estatística significante $(p>0,05)$ (tabela 4) na quantidade de PECI e PIC formados entre grupos TFDa 640, TFDa 320 e CHX. Porém, para os PECl, o grupo da CHX também não diferiu estatisticamente do tratado com solução salina ( $\mathrm{NaCl} 0,89 \%)$. No entanto, para esta comparação, o valor de $p$ foi de 0,07 , que é próximo do nível de significância adotado neste estudo Para PIC, os grupos TFDa 640, TFDa 320 e CHX diferiram estatisticamente do NaCl.

Tabela 3. Concentração de PECI e PIC de biofilme (S. mutans) de acordo com tratamento.

\begin{tabular}{|c|c|c|}
\hline \multirow{2}{*}{ Tratamentos/Grupos } & \multicolumn{2}{|c|}{$\mu \mathrm{g} / \mathrm{mm}^{2}$ (média \pm desvio padrão) } \\
\hline & PECI & PIC \\
\hline $\mathrm{CHX}(\mathrm{n}=2)$ & $1,08 \pm 0,18^{a b}$ & $0,19 \pm 0,06^{a}$ \\
\hline $\mathrm{NaCl}(\mathrm{n}=3)$ & $2,13 \pm 0,54^{b}$ & $0,50 \pm 0,18^{b}$ \\
\hline TFDa $320(n=3)$ & $0,66 \pm 0,14^{a}$ & $0,16 \pm 0,02^{a}$ \\
\hline TFDa $640(n=3)$ & $0,84 \pm 0,43^{a}$ & $0,13 \pm 0,02^{a}$ \\
\hline
\end{tabular}

Os dados são expressos como média (desvio padrão) da concentração de PECl e PIC pela área do espécime $\left(\mu \mathrm{g} / \mathrm{mm}^{2}\right)$. Nas colunas, as diferenças estatísticas são indicadas por letras minúsculas diferentes (teste de Tukey, $p<0,05$ ).

Tabela 4. Nível de significância entre os tratamentos em relação a viabilidade bacteriana, concentração de PECI e PIC: Tukey-Kramer

\begin{tabular}{ccccc} 
Comparação entre os tratamentos & $\begin{array}{c}\text { Viabilidade bacteriana } \\
\left(\mathbf{U F C} / \mathbf{m m}^{2}\right)\end{array}$ & $\begin{array}{c}\text { PECl } \\
\left(\boldsymbol{\mu g} / \mathbf{m m}^{2}\right)\end{array}$ & $\begin{array}{c}\text { PIC } \\
\left(\boldsymbol{\mu g} / \mathbf{m m}^{2}\right)\end{array}$ \\
\hline $\mathrm{CHX}$ & $\mathrm{NaCl}$ & $<.0001$ & 0,070 & 0,048 \\
$\mathrm{CHX}$ & TFDa 320 & 0.0014 & 0,648 & 0,989 \\
$\mathrm{CHX}$ & TFDa 640 & 0.0791 & 0,906 & 0,932 \\
$\mathrm{NaCl}$ & TFDa 320 & 0.0218 & 0,008 & 0,019 \\
$\mathrm{NaCl}$ & TFDa 640 & 0.0004 & 0,017 & 0,013 \\
TFDa 320 & TFDa 640 & 0.0218 & 0,931 & 0,987 \\
\hline
\end{tabular}

As médias de dois tratamentos são consideradas diferentes quando $p<0,05$.

Pelo método da coloração Gram, pode-se observar que houve contaminação, por algum tipo de micro-organismo, em apenas 1 poço do grupo $\mathrm{CHX}$, o qual foi eliminado do estudo. Esta coloração foi realizada regularmente e as lâminas foram observadas em microscópio óptico, por meio de lâminas com esfregaço inoculado, o qual mostraram apenas bactérias do tipo cocos coradas pela violeta de genciana, confirmando a pureza do biofilme por S. mutans (Figura 3). 


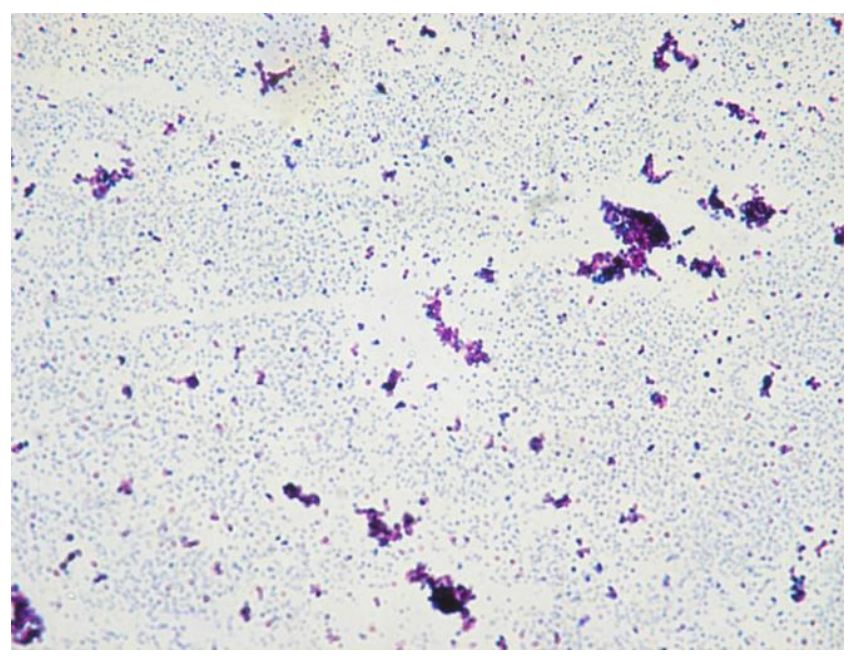

Figura 3. Coloração Gram. Presença de bactérias tipos cocos coradas por violeta genciana. 

Discussão 



\section{Discussão}

Os biofilmes bacterianos bucais estão envolvidos na etiologia da cárie dentária (Marsh, 2010) e reconhece-se que as bactérias de biofilmes são menos susceptíveis aos agentes antimicrobianos em comparação com bactérias planctônicas (Davey e O'Toole, 2000). O uso da terapia fotodinâmica para inativar micro-organismos é bem estudada (Zanin et al., 2005, 2006; Araújo et al., 2014) e os dados sugerem que a cárie dentária é uma doença susceptível a TFDa (Guglielmi et al., 2011; Melo et al., 2015). No entanto, fatores como os parâmetros de luz, o fotossensibilizador e de oxigênio tecidual são fatores indispensáveis para um tratamento bem sucedido usando TFDa. Neste estudo, avaliamos duas densidades de energia, combinadas com azul de toluidina, o fotossensibilizador mais empregado (Santin et al., 2014), em um S. mutans biofilme maduro e denso.

A fototoxicidade foi evidente em biofilmes expostos a TFDa, sugerindo um efeito de resposta dose-dependente do tempo de irradiação e da densidade de energia do laser de diodo utilizado, em relação à morte celular. Estes resultados corroboram com o estudo de Wilson et al. (1996) e Zanin et al. (2005), os quais utilizaram, respectivamente, laser de Arseneto de Gálio e Alumínio (GaAlAs) e laser Hélio-Neônio (HeNe), em diferentes densidades de energia, e os resultados mostraram que a quantidade de bactérias viáveis foi reduzida nos grupos que utilizaram densidade de energia maior. O'Neill et al. (2002) revelaram por meio de Microscopia Confocal de Varredura a Laser (CLSM), que a inativação fotodinâmica ocorre predominantemente nas camadas mais externas do biofilme deixando algumas das bactérias mais internas vivas, devido à incapacidade do corante se difundir para regiões mais internas, à incapacidade da luz penetrar, ou a combinação de ambos. presente estudo dobrou a densidade de energia e, consequentemente, dobrou o tempo de irradiação, deixando o biofilme exposto ao efeito da TFDa por mais tempo. Portanto as bactérias mais internas foram atingidas pela ação desta terapia.

Estudos na literatura que avaliaram o efeito da TFDa em biofilmes bacterianos, utilizaram como grupo controle para comparação, micro-organismos que foram submetidos aos efeitos isoladamente, ou da irradiação com a fonte de luz ou dos corantes. A maioria 
dos pesquisadores não observou resultados positivos, mostrando que há uma resistência microbiana à luz e que os corantes usados isoladamente não apresentaram efeito citotóxico para os micro-organismos testados (Wilson et al., 1996; O'Neill et al., 2002; Zanin et al., 2005, 2006; Bevilacqua et al., 2007; Costa et al., 2010; Pereira et al., 2011; Vahabi et al., 2011; Mang et al., 2012; Rolim et al., 2012; Silva et al., 2012; Araújo et al., 2014). Porém, no presente estudo, consideramos como grupo controle positivo, o digluconato de clorexidina $0,12 \%$, por apresentar efeito bactericida, diminuir a capacidade do biofilme para produzir ácidos e evitar o aumento da massa de biofilme (peso seco e proteínas totais), quando usada 2x ao dia (Ccahuana-Vásquez e Cury, 2010). Os efeitos da CHX 0,12\% sobre a viabilidade bacteriana foram semelhantes estatisticamente a TFDa $640 \mathrm{~J} / \mathrm{cm}^{2}$. Somente Müller et al. (2007) compararam a CHX e TFDa e revelaram que não ocorreram diferenças significativas da redução do números de bactérias, em biofilme multiespécies, entre grupos tratados com TFDa (laser Helbo e azul de metileno) e clorexidina a 0,2\%, porém teve uma diminuição significativa quando foi tratado com clorexidina a $2 \%$, mostrando um efeito antimicrobiano dose-dependente da clorexidina. Os dados da atual pesquisa sugerem que um tratamento duas vezes por dia com TFDa $640 \mathrm{~J} / \mathrm{cm}^{2}$ com azul de toluidina como fotossensibilizador é um mecanismo promissor para a inibição do desenvolvimento do biofilme rico em matriz.

Um biofilme é composto por uma matriz contendo polissacáridos (Sutherland, 2001). Os polissacarídeos extracelulares, especialmente os glucanos, são insolúveis e são sintetizados por S. mutans a partir da sacarose por ação das enzimas glicosiltransferases (GTase). Os PECI são considerados importantes para a formação do biofilme dental e na patogênese da cárie dentária (Hamada e Slade, 1980), por aumentarem a aderência dos micro-organismos, promoverem o crescimento do biofilme e serem responsáveis pela estrutura da matriz extracelular (Paes Leme et al., 2006; Bowen e Koo, 2011). Os resultados deste trabalho mostraram que a TFDa inibiu a produção de PECI de forma tão eficaz quanto a aplicação de $\mathrm{CHX} 0,12 \%$, sugerindo que os tratamentos com laser tiveram influência nestes fatores de virulência bacteriano na mesma proporção que a clorexidina. Além disso, 
o grupo da $\mathrm{CHX}$ também não diferiu estatisticamente do grupo tratado com $\mathrm{NaCl}$, e este diferiu estatisticamente de ambos os grupos da TFDa, podendo dificultar a interpretação dos dados. No entanto, quando os resultados foram avaliados em relação aos valores de $P$ ajustados, o nível de significância entre os grupos $\mathrm{CHX}$ e $\mathrm{NaCl}$ foi $\mathrm{p}=0,07$, o qual é um valor muito próximo do valor do nível de significância adotado (5\%).

Os PIC são compostos armazenadores tipo glicogênio que podem ser usados para produção de energia e convertidos em ácidos quando os açúcares livres não estão disponíveis na boca, prologando os períodos em que os biofilmes podem gerar ácidos, mantendo o pH baixo. (Hamada e Slade, 1980; Marsh e Nyvad, 2008). Uma tendência semelhante foi obtida para os dois polissacáridos estudados, uma vez que TFDa foi capaz de inibir PIC tão eficazmente quanto ao controle positivo (CHX), o que sugere a indução de morte celular. Assim, a irradiação nos parâmetros utilizados em nosso estudo parecem inibir o metabolismo bacteriano.

Ccahuana-Vásquez e Cury (2010) mostraram que o tratamento com CHX 0,12\% diminui a quantidade de bactérias viáveis e que a redução na quantidade de polissacarídeos extracelulares, deve ser atribuída à morte bacteriana e não a um efeito específico de $\mathrm{CHX}$ em inibir a sua síntese. Koo et al. (2003) relataram que a clorexidina não tem ação sobre a inibição da síntese de enzimas glicosiltransferases, e consequentemente efeito sobre a quantidade de polissacárideos nos biofilmes, interferindo somente no desenvolvimento de $S$. mutans no biofilme. Não há na literatura estudos que analisem o efeito da terapia fotodinâmica antimicrobiana sobre os polissacarídeos, porém esta perturbação da matriz poderia indicar que há uma diminuição da expressão de enzimas que sintetizam os $\mathrm{PECl}$ (glicosiltransferases) ou uma desmontagem do polissacárido em moléculas menores por efeito da TFDa. Estas hipóteses serão investigadas em estudos futuros.

Existem na literatura estudos que demonstraram que as bactérias bucais são susceptíveis a TFDa, quando são cultivadas em culturas planctônicas (Williams et al., 2003; Bevilacqua et al., 2007; Costa et al., 2010), e quando estão na forma de biofilmes (Zanin et al., 2005, 2006; Pereira et al., 2011; de Melo et al., 2013). A organização das bactérias 
dentro da boca estão como biofilme. Sabe-se que as células cultivadas em biofilme diferem das culturas planctônicas em certos aspectos, incluindo a presença de substâncias poliméricas extracelulares, a composição da parede celular, a taxa de crescimento, a atividade metabólica e de expressão de genes (Costerton et al., 1999).

O modelo de formação de biofilme in vitro utilizado neste estudo foi baseado no trabalho de Ccahuana-Vásquez e Cury (2010), o qual utilizou cepas de S. mutans e as expôs a grande quantidade de açúcar, 8x/dia, durante um pequeno período de tempo, com o objetivo de simular o que acontece na cavidade bucal. Esse método validado é conhecido como "Miséria e Fartura" e pode ser usado para testar os efeitos dos agentes antimicrobianos no crescimento do biofilme dental monoespécie. Considerando-se que o metabolismo do açúcar é essencial para o comportamento de S. mutans (Hamada e Slade, 1980), este modelo foi apropriado desde que, a sacarose foi usada para produzir PECI que formam a matriz do biofilme e para o armazenamento de PIC, para agir como reservatório. No entanto, cada modelo descreve a dinâmica de um determinado processo e os modelos não podem descrever todos os aspectos da doença (Bowen, 2015). Outros estudos devem ser realizados, a fim de simular as condições intra-bucais complexas.

Neste estudo, observou-se que a TFDa foi capaz de diminuir o número de bactéria viáveis em UFC/mm ${ }^{2}$ em um modelo de biofilme. Estudos similares, usando o laser de baixa potência e o corante azul de toluidina, também mostraram efeitos positivos em relação a TFDa, a qual foi eficaz em reduzir significativamente a viabilidade bacteriana de biofilme de S. mutans (Zanin et al., 2005; Vahabi et al., 2011) e multiespécies (O’Neill et al., 2002). Os fotossensibilizadores são elementos essenciais na TFDa. O azul de toluidina é uma opção atraente por causa de seu custo acessível e intensa absorção no espectro de onda vermelho (> $600 \mathrm{~nm}$ ) (Lima et al., 2009), além de interagir mais facilmente com a parede celular das bactérias, devido a sua maior solubilidade na região hidrofóbica da parede e ter peso molecular baixo permitindo-se difundir (Rolim et al., 2012). A efetividade da TFDa é claramente dependente da composição do revestimento bacteriano. De modo geral, as bactérias Gram-positivas, com o S. mutans, costumam ser mais susceptíveis à TFDa do que 
as Gram-negativas. A parede celular das bactérias Gram-positivas têm poros de peptideoglicanos e ácidos lipoteicoicos que possibilitam a passagem do fotossensibilizador, dando assim amplo acesso à membrana citoplasmática (Dai et al., 2009).

Sob as condições testadas no presente estudo, a terapia fotodinâmica suprime o desenvolvimento de biofilmes e apresenta efeitos sobre a concentração de polissacarídeo. Mais pesquisas são necessárias para avaliar o mecanismo da TFDa e seus efeitos na estrutura dos polissacarídeos. 



$$
\text { - }
$$





\section{CONCLUSÃo}

A Terapia Fotodinâmica antimicrobiana (TFDa), utilizando laser de baixa potência (InGaAIP) a uma densidade de $640 \mathrm{~J} / \mathrm{cm}^{2}$ associado ao azul de toluidina, foi capaz de reduzir significativamente o número de bactérias viáveis em biofilme de S. mutans cultivados in vitro e interferir na formação de polissacarídeos extracelulares insolúveis e intracelulares. 

$R_{\text {eferências }}$ 



\section{REFERÊNCIAS}

Aires CP, Del Bel Cury AA, Tenuta LM, Klein MI, Koo H, Duarte S, Cury JA. Effect of starch and sucrose on dental biofilm formation and on root dentine demineralization. Caries Res 2008;42:380-6.

Al-Watban FA, Zhang $X Y$. Photodynamic therapy of human undifferentiated thyroid carcinoma-bearing nude mice using topical 5-aminolevulinic acid. Photomed Laser Surg 2005;23:206-11.

Almeida PF, Franca MP, Santos SP, Moreira RS, Tunes UR. Microbiota estreptocócica associada com a formação inicial da placa dental. Rev Cienc Med Biol 2002;1:33-41.

Araújo NC, Fontana CR, Bagnato VS, Gerbi ME. Photodynamic antimicrobial therapy of curcumin in biofilms and carious dentine. Lasers Med Sci 2014;29:629-35.

Autio-Gold J. The role of chlorhexidine in caries prevention. Oper Dent 2008;33:710-6.

Bevilacqua IM, Nicolau RA, Khouri S, Brugnera A Jr, Teodoro GR, Zângaro RA, Pacheco MT. The impact of photodynamic therapy on the viability of Streptococcus mutans in a planktonic culture. Photomed Laser Surg 2007;25:513-8.

Bowen WH. Dental caries - not just holes in teeth! A perspective. Mol Oral Microbiol 2015;7:1-6.

Bowen WH, Koo H. Biology of Streptococcus mutans-derived glucosyltransferases: role in extracellular matrix formation of cariogenic biofilms. Caries Res 2011;45:69-86.

Ccahuana-Vásquez RA, Cury JA. S. mutans biofilm model to evaluate antimicrobial substances and enamel demineralization. Braz Oral Res 2010;24:135-41.

Costa AC, Chibebe Junior J, Pereira CA, Machado AK, Beltrame Junior M, Junqueira JC, Jorge AO. Susceptibility of planktonic cultures of Streptococcus mutans to photodynamic therapy with a light-emitting diode. Braz Oral Res 2010;24:413-8.

Costerton JW, Stewart PS, Greenberg EP. Bacterial biofilms: a common cause of persistent infections. Science 1999;284:1318-22.

Cury JA, Rebello MA, Del Bel Cury AA. In situ relationship between sucrose exposure and the composition of dental plaque. Caries Res 1997;31:356-60.

Dai T, Huang YY, Hamblin MR. Photodynamic therapy for localized infections--state of the art. Photodiagnosis Photodyn Ther 2009;6:170-88.

Davey ME, O'toole GA. Microbial biofilms: from ecology to molecular genetics. Microbiol Mol Biol Rev 2000; 64:847-67.

de Melo MA, Rolim JP, Zanin IC, Barros EB, da-Costa EF, Rodrigues LK. Characterization of antimicrobial photodynamic therapy-treated Streptococci mutans: an atomic force microscopy study. Photomed Laser Surg 2013;31:105-9.

Dougherty TJ, Gomer CJ, Henderson BW, Jori G, Kessel D, Korbelik M, Moan J, Peng Q. Photodynamic therapy. J Natl Cancer Inst 1998;90:889-905. 
Dubois M, Gillis KA, Hamilton JK, Rebers PA, Smith F: Colorimetric method for determination of sugars and related substances. Analyt Chem 1956;28:350-6.

Gad F, Zahra T, Hasan T, Hamblin MR. Effects of growth phase and extracellular slime on photodynamic inactivation of gram-positive pathogenic bacteria. Antimicrob Agents Chemother 2004;48:2173-8.

Guglielmi C de A, Simionato MR, Ramalho KM, Imparato JC, Pinheiro SL, Luz MA. Clinical use of photodynamic antimicrobial chemotherapy for the treatment of deep carious lesions. $J$ Biomed Opt 2011;16:0880031-7.

Hamada S, Slade HD. Biology, immunology, and cariogenicity of Streptococcus mutans. Microbiol Rev 1980;44:331-84.

Hamblin MR, Hasan T. Photodynamic therapy: a new antimicrobial approach to infectious disease? Photochem Photobiol Sci 2004;3:436-50.

Jones CG. Chlorhexidine: is it still the gold standard? Periodontol 2000 1997;15:55-62.

Koo H, Hayacibara MF, Schobel BD, Cury JA, Rosalen PL, Park YK, Vacca-Smith AM, Bowen WH. Inhibition of Streptococcus mutans biofilm accumulation and polysaccharide production by apigenin and tt-farnesol. J Antimicrob Chemother 2003;52:782-9.

Kurek A, Grudniak AM, Kraczkiewicz-Dowjat A, Wolska KI. New antibacterial therapeutics and strategies. Pol J Microbiol 2011;60:3-12.

Lemos JA, Burne RA. A model of efficiency: stress tolerance by Streptococcus mutans. Microbiology 2008;154:3247-55.

Lima JPM, Sampaio de Melo MA, Borges FMC, Teixeira AH, Steiner-Oliveira C, Nobre dos Santos M, Rodrigues LKA, Zanin ICJ. Evaluation of the antimicrobial effect of photodynamic antimicrobial therapy in an in situ model of dentine caries. Eur J Oral Sci 2009;117:568-74.

Löe $\mathrm{H}$. Oral hygiene in the prevention of caries and periodontal disease. Int Dent $\mathrm{J}$ 2000;50:129-39.

Mang TS, Tayal DP, Baier R. Photodynamic therapy as an alternative treatment for disinfection of bacteria in oral biofilms. Lasers Surg Med 2012;44:588-96.

Marsh PD, Bradshaw DJ. Physiological approaches to the control of oral biofilms. Adv Dent Res 1997;11:176-85.

Marsh PD, Nyvad B. The oral microbiota and dental biofilms. In: Fejerskov O, Kidd E. Dental Caries: The Disease and its Clinical Management. Blackwell Munksgaard Ltd; 2008. p. 16387.

Marsh PD. Microbiology of dental plaque biofilms and their role in oral health and caries. Dent Clin North Am 2010;54:441-54.

Melo MA, Rolim JP, Passos VF, Lima RA, Zanin IC, Codes BM, Rocha SS, Rodrigues LK. Photodynamic antimicrobial chemotherapy and ultraconservative caries removal linked for management of deep caries lesions. Photodiagnosis Photodyn Ther 2015;29.pii: S15721000.

Müller P, Guggenheim B, Schmidlin PR. Efficacy of gasiform ozone and photodynamic therapy on a multispecies oral biofilm in vitro. Eur J Oral Sci 2007;115:77-80. 
Núñez SC, Ribeiro MS, Garcez AS. PDT - Terapia Fotodinâmica Antimicrobiana na Odontologia. Rio de Janeiro: Ed. Elsevier; 2013.

O'Neill JF, Hope CK, Wilson M. Oral bacteria in multi-species biofilms can be killed by red light in the presence of toluidine blue. Lasers Surg Med 2002;31:86-90.

Paes Leme AF, Koo H, Bellato CM, Bedi G, Cury JA. The role of sucrose in cariogenic dental biofilm formation-new insight. J Dent Res 2006;85:878-87.

Pereira CA, Romeiro RL, Costa AC, Machado AK, Junqueira JC, Jorge AO. Susceptibility of Candida albicans, Staphylococcus aureus, and Streptococcus mutans biofilms to photodynamic inactivation: an in vitro study. Lasers Med Sci 2011;26:341-8.

Parisotto TM, Stipp R, Rodrigues LK, Mattos-Graner RO, Costa LS, Nobre-Dos-Santos M. Can insoluble polysaccharide concentration in dental plaque, sugar exposure and cariogenic microorganisms predict early childhood caries? A follow-up study. Arch Oral Biol 2015;60:1091-7.

Petersen PE. The World Oral Health Report 2003: continuous improvement of oral health in the 21st century-the approach of the WHO Global Oral Health Programme. Community Dent Oral Epidemiol 2003;31 Suppl 1:3-23.

Pratten J, Wilson M, Spratt DA. Characterization of in vitro oral bacterial biofilms by traditional and molecular methods. Oral Microbiol Immunol 2003;18:45-9.

Rolim JP, de-Melo MA, Guedes SF, Albuquerque-Filho FB, de Souza JR, Nogueira NA, Zanin IC, Rodrigues LK. The antimicrobial activity of photodynamic therapy against Streptococcus mutans using different photosensitizers. J Photochem Photobiol B 2012;106:40-6.

Rölla G, Melsen B. On the mechanism of the plaque inhibition by chlorhexidine. J Dent Res 1975;54:B57-62.

Santin GC, Oliveira DS, Galo R, Borsatto MC, Corona SA. Antimicrobial photodynamic therapy and dental plaque: a systematic review of the literature. Scientific World Journal 2014;2014:824538.

Schneider M, Kirfel G, Berthold M, Frentzen M, Krause F, Braun A. The impact of antimicrobial photodynamic therapy in an artificial biofilm model. Lasers Med Sci 2012;27:615-20.

Silva TC, Pereira AF, Exterkate RA, Bagnato VS, Buzalaf MA, Machado MA, Ten Cate JM, Crielaard W, Deng DM. Application of an active attachment model as a high-throughput demineralization biofilm model. J Dent 2012;40:41-7.

Sutherland I. Biofilm exopolysaccharides: a strong and sticky framework. Microbiology 2001;147:3-9.

Svensäter G, Borgström M, Bowden GH, Edwardsson S. The acid-tolerant microbiota associated with plaque from initial caries and healthy tooth surfaces. Caries Res 2003;37:395-403.

Takahashi N, Nyvad B. The role of bacteria in the caries process: ecological perspectives. $J$ Dent Res 2011;90:294-303. 
Tenuta LM, Ricomini Filho AP, Del Bel Cury AA, Cury JA. Effect of sucrose on the selection of mutans streptococci and lactobacilli in dental biofilm formedin situ. Caries Res 2006;40:546-9.

Vahabi S, Fekrazad R, Ayremlou S, Taheri S, Zangeneh N. The effect of antimicrobial photodynamic therapy with radachlorin and toluidine blue on Streptococcus mutans: an in vitro study. J Dent (Tehran) 2011;8:48-54.

van Houte J. Role of micro-organisms in caries etiology. J Dent Res 1994;73:672-81.

Wainwright M. Photodynamic antimicrobial chemotherapy (PACT). J Antimicrob Chemother 1998;42:13-28.

Weishaupt KR, Gomer CJ, Dougherty TJ. Identification of singlet oxygen as the cytotoxic agent in photoinactivation of a murine tumor. Cancer Res 1976;36:2326-9.

Williams JA, Pearson GJ, Colles MJ, Wilson M. The effect of variable energy input from a novel light source on the photoactivated bactericidal action of toluidine blue $\mathrm{O}$ on Streptococcus mutans. Caries Res 2003;37:190-3.

Wilson BC, Patterson MS. The physics of photodynamic therapy. Phys Med Biol 1986;31:327-60.

Wilson M, Burns T, Pratten J. Killing of Streptococcus sanguis in biofilms using a lightactivated antimicrobial agent. J Antimicrob Chemother 1996;37:377-81.

Zanatta FB, Rösing CK. Clorexidina: mecanismo de ação e evidências atuais de sua eficácia no contexto do biofilme supragengival. Scientific-A 2007;1:35-43.

Zanin IC, Gonçalves RB, Junior AB, Hope CK, Pratten J. Susceptibility of Streptococcus mutans biofilms to photodynamic therapy: an in vitro study. $J$ Antimicrob Chemother 2005;56:324-30.

Zanin ICJ, Lobo MM, Rodrigues LKA, Pimenta LAF, Ho'fling JF, Gonçalves RB. Photosensitization of in vitro biofilms by toluidine blue $\mathrm{O}$ combined with a light-emitting diode. Eur J Oral Sci 2006;114:64-69. 